\title{
Initial results of selective renal parenchymal clamping with an adjustable kidney clamp in nephron-sparing surgery: an easy way to minimise renal ischaemia
}

\author{
KC Cheng, MK Yiu, SH Ho, TL Ng, HL Tsu, WK Ma *
}

\section{A B S T R A C T}

Introduction: A renal parenchymal clamp has been used at our centre since March 2012. It is used in position over the kidney to achieve optimal vascular control of a tumour while minimising parenchymal ischaemia. This study aimed to report the feasibility, surgical outcome, and oncological control of a kidney clamp in partial nephrectomy.

Methods: This study was conducted at a teaching hospital in Hong Kong. Partial nephrectomies performed from January 2009 to March 2015 were reviewed. The tumour characteristics and surgical outcomes of kidney clamp were studied and compared with traditional hilar clamping.

Results: A total of 92 patients were identified during the study period. Kidney clamps were used in 20 patients and hilar clamping in 72 , with a mean follow-up of 27 and 37 months, respectively. For patients in whom a kidney clamp was applied, all tumours were exophytic to a different extent and the majority (90\%) were located at the polar region. The PADUA (preoperative aspects and dimensions used

This article was published on $29 \mathrm{Jul}$ 2016 at www.hkmj.org. for an anatomical) classification nephrometry score was also lower than those in whom hilar clamping was used ( 7.07 vs $8.34 ; \mathrm{P}=0.002)$. The clamp was used in open, laparoscopic, and robot-assisted surgery. Operating time was shorter $(207 \pm 72$ mins vs 306 \pm 80 mins; $\mathrm{P}<0.001)$ and estimated blood loss was lower $(205 \pm 191 \mathrm{~mL}$ vs $331 \pm 275 \mathrm{~mL}$; $\mathrm{P}=0.045)$ with kidney clamp. No acute kidney injury occurred. Postoperative renal function was comparable between the two groups.

Conclusions: Partial nephrectomy using parenchymal clamping is safe and feasible in selected cases. The postoperative renal function and oncological control were satisfactory.

\section{Hong Kong Med J 2016;22:563-9}

DOI: 10.12809/hkmj154746

KC Cheng, MB, ChB

MK Yiu, FHKAM (Surgery)

SH Ho, FHKAM (Surgery)

TL Ng, FHKAM (Surgery)

HL Tsu, FHKAM (Surgery)

WK Ma *, FHKAM (Surgery)

Department of Surgery, Li Ka Shing Faculty of Medicine, The University of Hong Kong, Queen Mary Hospital, Pokfulam, Hong Kong

*Corresponding author: kitkitma@yahoo.com

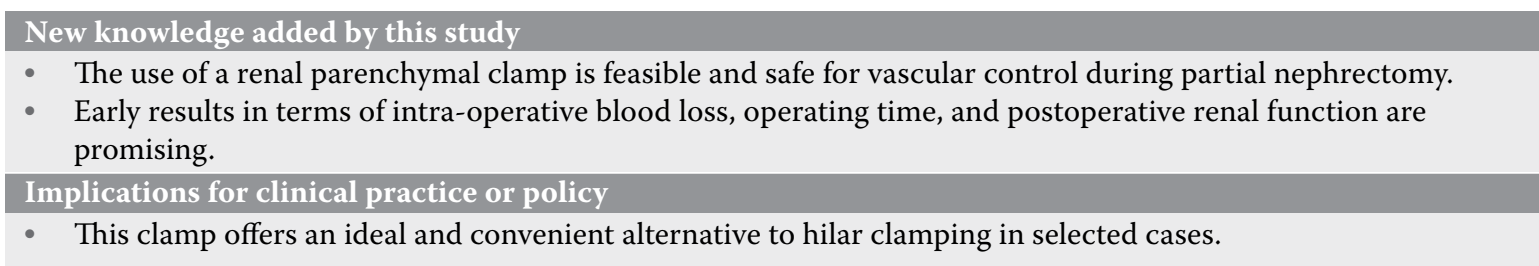

\section{Introduction}

Nephron-sparing surgery (NSS) for renal tumour has been proved to produce similar oncological and superior functional outcome for stage $\mathrm{T} 1$ renal masses as radical nephrectomy. ${ }^{1}$ It is now recommended as the gold standard. ${ }^{2}$ Various vascular control methods have been described to achieve a bloodless field for tumour dissection and excision, with the traditional way being renal hilar clamping $(\mathrm{HC})$ that results in global renal ischaemia. The importance of minimising ischaemia in NSS to preserve postoperative renal function is well documented. ${ }^{3}$ While $\mathrm{HC}$ is less technically demanding, zero-ischaemia NSS with selective segmental arterial clamping requires high levels of surgical and anaesthetic expertise. ${ }^{1}$ Furthermore, not all renal masses are amenable to the technique, such as peripherally located tumours without an identifiable feeding segmental artery on preoperative imaging. In such cases, attaining regional renal ischaemia is a feasible way of maintaining a clear operative field while reducing ischaemic insults to the renal parenchyma, and will theoretically better preserve postoperative renal function. Different methods of regional ischaemia have been reported including manual compression and various parenchymal clamps. ${ }^{4}$ We describe a method of selective renal parenchymal clamping (SRPC) with a kidney clamp 


\section{利用可調節腎鉗進行局部腎腫瘤切除的初期 報告：一個減少腎臟缺血的簡單方法 \\ 鄭冠中、姚銘廣、何思影、吳翠蓮、徐學良、馬偉傑}

引言：自2012年3月, 我們醫院的泌尿外科部已開始使用腎鉗, 讓腫 瘤血管得到最佳控制, 同時減少腎組織缺血的發生。本文報告利用腎 鉗進行局部腎腫瘤切除的可行性、手術結果及腫瘤控制。

方法: 這回顧性研究於香港一所大學教學醫院的泌尿外科部進行, 檢 視2009年1月至2015年3月期間進行局部腎腫瘤切除的記錄, 並將使 用腎鉗與傳統阻斷臂動脈方法在腫瘤特質和手術結果進行比較。

結果 : 研究期間共92名病人接受局部腎腫瘤切除, 其中 20 例使用腎 鉗, 另 72 例採用傳統阻斷臂動脈方法, 術後隨訪平均分別為 27 和 37 個月。腎鉗在開放式、腹腔鏡和機器人輔助的外科手術中使用。與 傳統阻斷臂動脈的病人比較, 使用腎鉗的病人的腫瘤均屬不同程度 的外生性, 有九成位於腎臟上下極範圍。其術前解剖學參數（PADUA）分類系統的分數較低 $(7.07$ 比 $8.34 ; \mathrm{P}=0.002)$, 手術時間較短 $(207 \pm 72$ 分鐘比 $306 \pm 80$ 分鐘 $; \mathrm{P}<0.001)$, 失血量亦較少 $(205 \pm$ 191 毫升比 $331 \pm 275$ 毫升； P=0.045）。沒有病人術後出現急性腎衰 竭。兩組的術後腎功能相若。

結論：在選擇病例中利用腎鉗進行局部腎腫瘤切除是安全及可行的。 術後腎功能及腫瘤控制均令人滿意。

that can be adopted in open, conventional, or robotassisted laparoscopic NSS. In this study, we report the case selection, feasibility, and surgical outcomes in our initial series of SRPC technique with respect to traditional HC NSS.

\section{Methods}

All patients who underwent NSS for renal tumour from January 2009 to March 2015 were retrospectively reviewed at a tertiary centre in Hong Kong. Since March 2012, selected patients have been prospectively recruited for SRPC after careful review of the computed tomographic imaging during a preoperative planning session. Eligible indications for renal parenchymal clamping included small tumour size, and peripherally located and exophytic tumour; hilar or centrally located tumours were unsuitable. All procedures including open, conventional, and robot-assisted laparoscopic transperitoneal or retroperitoneal approaches were included. Patients with NSS performed using selective segmental artery clamping technique were excluded from the current study. This study was done in accordance with the principles outlined in

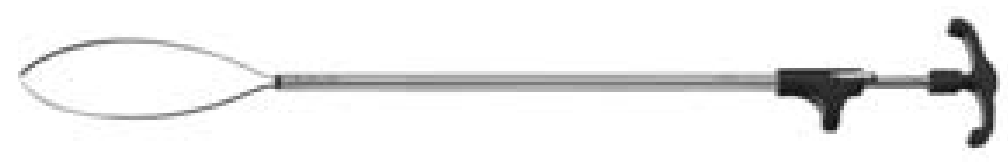

FIG I. The design of the kidney clamp the Declaration of Helsinki.

\section{The kidney clamp}

The technique of SRPC has been in use at our unit since March 2012. The kidney clamp (Karl Storz, Tuttlingen, Germany) is a 29-cm long, $10-\mathrm{mm}$ wide instrument. It consists of a $120-\mathrm{mm}$ long distal snare comprising nitinol, an outer sheath, and a handle with ratchet (Fig 1). It is reusable and can be inserted through a $10-\mathrm{mm}$ laparoscopic port. It can be used in laparoscopic, robot-assisted, or open NSS in both transperitoneal and retroperitoneal approach. Tightening of the snare across the renal parenchyma surrounding the tumour occludes the blood flow with the ratchet preventing accidental loosening of the snare during dissection. The clamp can be released by rotating the handle 90 degrees. The fine ratchet mechanism of the clamp allows easy fine-tuning of tightness on the parenchymal tissue according to the bleeding encountered during tumour excision, as the ratchet can be further tightened one gear tooth at a time. Furthermore, the clamp release is gradual and can be easily tightened again. This allows further haemostasis procedures to be performed in case bleeding is encountered on clamp release.

\section{The nephron-sparing surgery with selective renal parenchymal clamping}

The partial nephrectomy procedure was carried out in a standardised way via an open, pure laparoscopic, or robot-assisted laparoscopic approach. Intraoperative ureteric cannulation and catheterisation was performed after general anaesthesia in selected patients whose tumours were considered by the operating surgeon to be closer to the collecting system. With the patient positioned in a lateral bridged position, an open oblique loin or subcostal incision along the 12th rib tip was made or laparoscopic ports were inserted in the standard manner according to the selected approach. After creation of the operative field and exposure of the kidney, the Gerota's fascia was incised and perirenal fat was dissected from the renal capsule. Hilar dissections were performed in all cases in order to prepare for $\mathrm{HC}$ in case excessive bleeding was encountered. The renal tumour was exposed with its circumferential and deep margins confirmed by intra-operative ultrasonography. The perirenal fat was dissected adequately to allow positioning of the parenchymal clamp over the kidney at about 1 to 1.5 $\mathrm{cm}$ from the tumour edge so as to achieve optimal vascular control while avoiding slipping of the clamp during repair of the parenchymal defect after tumour excision. In laparoscopic procedures, the clamp was inserted through a $10-\mathrm{mm}$ assistant port directed towards the planned axis of clamping across the polar region (Fig 2). The hilar area and the ureter were always spared from clamping. The snare was 


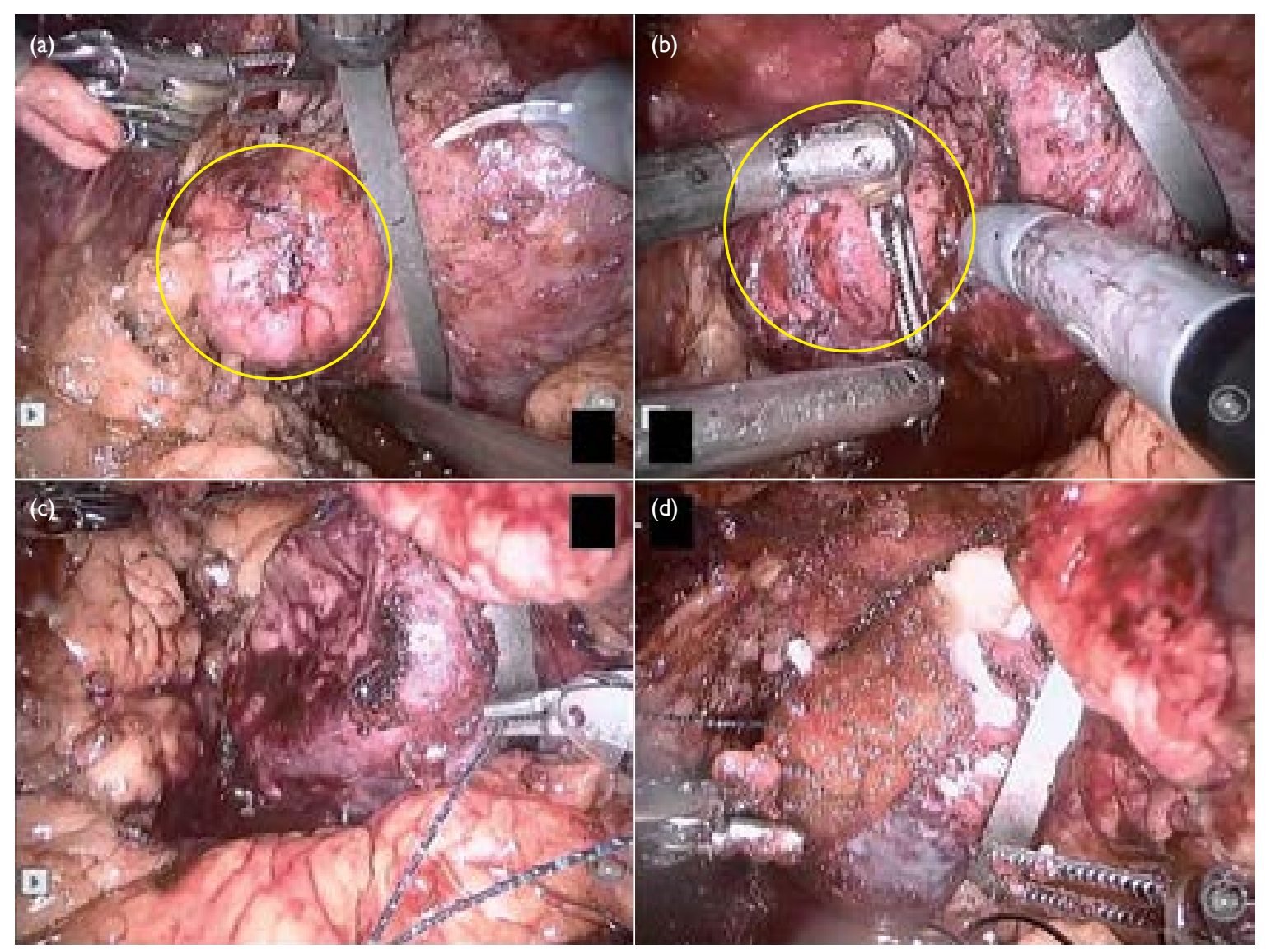

FIG 2. Intra-operative photos showing application of the parenchymal clamp in a robot-assisted laparoscopic partial nephrectomy

(a) Parenchymal clamp being placed across the polar region with kidney tumour (circled in yellow) dissected free from perirenal fat;

(b) excision of tumour (circled in yellow) in a bloodless field with parenchymal clamp tightened; (c) renorrhaphy with barbed suture;

(d) completion of renorrhaphy with fibrin glue and parenchymal clamp released

then tightened gradually until bluish discolouration of the parenchyma was noted, and the tightness adjusted according to the degree of bleeding during tumour excision. A thermal excision of tumour was performed. Breaching of the collecting system was checked in those patients with retrograde stenting by slightly releasing the clamp and injecting methylene blue dye through the ureteric catheter, and any area of leakage repaired with polydioxanone sutures. Renorrhaphy was done by using a barbed suture in a continuous manner, with reinforcement by sliding polymer clips. Fibrin glue was applied to aid haemostasis in selected patients, and the kidney clamp was loosened once major oozing had stopped, but kept in place providing stability for the renorrhaphy before its final removal, such that regional ischaemic time could be minimised.

\section{Data collection and analysis}

Patient demographics (age, gender, Charlson Comorbidity Index score, baseline renal function, co-existing diabetes or hypertension), tumour characteristics (radiological maximum tumour diameter, PADUA [preoperative aspects and dimensions used for an anatomical] nephrometry score), intra-operative data (operating time, ischaemic time, estimated blood loss), and postoperative outcomes (complications, hospital stay, renal function) were assessed for all patients. Estimated glomerular filtration rate (eGFR) using Modification of Diet in Renal Disease study equation was used to measure postoperative renal function. ${ }^{5}$ Acute kidney injury was defined as either twofold increase in serum creatinine or $50 \%$ reduction in eGFR within the postoperative hospital stay when compared with preoperative baseline, or any requirement for renal replacement therapy. The renal function at 7, 30, 60, and 90 days after operation was assessed. The PADUA nephrometry score ${ }^{6}$ was used as an objective measure of tumour characteristics and its individual parameters were also analysed. Complications were graded as per the Clavien-Dindo classification system. ${ }^{7}$ The proportion of high-grade complications (grades 3-5) was reported.

Clinical data were compared between the SRPC series and a larger cohort of conventional HC 
series. Continuous variables were compared using Mann-Whitney $U$ test while categorical variables were compared using Chi squared test or Fisher's exact test. Statistical significance was defined as $\mathrm{P}<0.05$. Analysis was performed using the Statistical Package for the Social Sciences (Windows version 20.0; SPSS Inc, Chicago [IL], US).

\section{Results}

From January 2009 to March 2015, a total of 93 patients were identified. After excluding one patient who had an infected upper moiety in a duplex system with upper pole nephrectomy, 92 cases with NSS procedures performed with conventional $\mathrm{HC}$ $(n=72)$ or SRPC $(n=20)$ techniques were included for analysis. The mean follow-up duration was 27 and 37 months for SRPC and HC groups, respectively. Patient demographics and co-morbidity were similar between the two groups, as was baseline renal function (mean \pm standard deviation of eGFR: $79.1 \pm 25.9 \mathrm{~mL} / \mathrm{min}$ vs $76.1 \pm 26.5 \mathrm{~mL} / \mathrm{min} ; \mathrm{P}=0.751$; Table 1). Regarding the tumour complexity (Table 2), there were no differences in the mean radiological tumour size $(26.1 \pm 10.6 \mathrm{~mm}$ vs $30.6 \pm 15.2 \mathrm{~mm}$ $\mathrm{P}=0.371$ ), while the mean PADUA nephrometry score was significantly lower in the SRPC group (7.07 vs $8.34 ; \mathrm{P}=0.002$ ). All tumours in the SRPC series were significantly more exophytic to varying extents $(\mathrm{P}=0.032)$, laterally located $(\mathrm{P}=0.015)$, and over the polar region $(\mathrm{P}=0.016)$. Apparently more NSS procedures in the SRPC group were performed by laparoscopic approach (with or without robot assistance), though not reaching statistical significance compared with HC group. (Table 3). Operating time was significantly shorter (207 \pm 72 mins vs $306 \pm 80$ mins; $\mathrm{P}<0.001)$ and estimated blood loss was lower $(205 \pm 191 \mathrm{~mL}$ vs $331 \pm 275$ $\mathrm{mL} ; \mathrm{P}=0.045)$ with SRPC. No open conversions were needed in minimally invasive approaches. The mean length of hospital stay was 6.6 days and complication rate with Clavien-Dindo grade 3 or above was $5 \%$ $(n=1)$ for SRPC group.

Overall postoperative renal function was satisfactory in both groups and the changes between preoperative and postoperative eGFR are shown in Table 4. Cold and warm ischaemia was adopted in $50(69.4 \%)$ and $22(30.6 \%)$ patients in the $\mathrm{HC}$ group, respectively. The mean clamping time for SRPC was 20 minutes. The reduction in eGFR was significantly more for $\mathrm{HC}$ at postoperative day 60 for

TABLE I. Patient demographics and preoperative renal function

\begin{tabular}{lccc}
\hline & SRPC (n=20) & HC (n=72) & P value \\
\hline Mean age (years) & 59.5 & 59.3 & 0.660 \\
Female & $55.0 \%$ & $38.9 \%$ & 0.213 \\
Diabetes mellitus & $15.0 \%$ & $20.8 \%$ & 0.753 \\
Hypertension & $45.0 \%$ & $44.4 \%$ & 1.000 \\
Charlson Comorbidity Index* & $2.9 \pm 2.75$ & $3.08 \pm 2.00$ & 0.394 \\
Preoperative eGFR (mL/min) & $79.1 \pm 25.9$ & $76.1 \pm 26.5$ & 0.751 \\
\hline
\end{tabular}

Abbreviations: eGFR = estimated glomerular filtration rate; $\mathrm{HC}=$ hilar clamping; SRPC = selective renal parenchymal clamping

* Mean \pm standard deviation

TABLE 2. Tumour characteristics

\begin{tabular}{|c|c|c|c|}
\hline & SRPC (n=20) & HC (n=72) & P value \\
\hline Mean ( \pm standard deviation) radiological tumour size $(\mathrm{mm})$ & $26.1 \pm 10.6$ & $30.6 \pm 15.2$ & 0.371 \\
\hline Longitudinal tumour location & & & 0.016 \\
\hline Upper/lower pole (\%) & 90.0 & 61.1 & \\
\hline Middle pole (\%) & 10.0 & 38.9 & \\
\hline Medial/lateral tumour & & & 0.015 \\
\hline Medial (\%) & 7.7 & 42.6 & \\
\hline Lateral (\%) & 92.3 & 57.4 & \\
\hline \multicolumn{4}{|l|}{ Tumour deepening into parenchyma } \\
\hline Entirely endophytic & 0 & 20.3 & 0.032 \\
\hline$<50 \%$ Exophytic & 36.8 & 39.0 & \\
\hline$\geq 50 \%$ Exophytic & 63.2 & 40.7 & \\
\hline Mean PADUA nephrometry score & 7.07 & 8.34 & 0.002 \\
\hline
\end{tabular}

Abbreviations: $\mathrm{HC}=$ hilar clamping; PADUA = preoperative aspects and dimensions used for an anatomical; SRPC = selective renal parenchymal clamping 
TABLE 3. Surgical outcomes and complications

\begin{tabular}{|c|c|c|c|}
\hline & SRPC (n=20) & HC (n=72) & $P$ value \\
\hline Surgical approach & & & 0.07 \\
\hline Open & $35.0 \%$ & $68.1 \%$ & \\
\hline Robot-assisted laparoscopic & $45.0 \%$ & $31.9 \%$ & \\
\hline Pure laparoscopic & $20.0 \%$ & 0 & \\
\hline Mean ( \pm standard deviation) operating time (mins) & $207 \pm 72$ & $306 \pm 80$ & $<0.001$ \\
\hline Mean ( \pm standard deviation) estimated blood loss $(\mathrm{mL})$ & $205 \pm 191$ & $331 \pm 275$ & 0.045 \\
\hline Mean length of hospital stay (days) & 6.6 & 8.9 & 0.094 \\
\hline \multicolumn{4}{|l|}{ Complications } \\
\hline Overall & $40 \%$ & $36.1 \%$ & 0.797 \\
\hline Clavien-Dindo $\geq$ grade 3 & $5 \%$ & $2.8 \%$ & 1.000 \\
\hline
\end{tabular}

Abbreviations: $\mathrm{HC}=$ hilar clamping; $\mathrm{SRPC}=$ selective renal parenchymal clamping

TABLE 4. Renal function outcomes

\begin{tabular}{|c|c|c|c|c|c|}
\hline & SRPC $(n=20)$ & $\begin{array}{c}\text { HC - cold } \\
\text { ischaemia }(n=50)\end{array}$ & P value* & $\begin{array}{c}\text { HC - warm } \\
\text { ischaemia }(n=22)\end{array}$ & $P$ value \\
\hline \multicolumn{6}{|l|}{ Mean ischaemic time (mins) } \\
\hline Warm ischaemic time & N/A & $\mathrm{N} / \mathrm{A}$ & & 27.5 & \\
\hline Cold ischaemic time & N/A & 63.2 & & $\mathrm{~N} / \mathrm{A}$ & \\
\hline Regional clamp time & 20 & N/A & & N/A & \\
\hline \multicolumn{6}{|l|}{ Postoperative renal function } \\
\hline Acute kidney injury (\%) & 0 & 13.5 & & 0 & \\
\hline \multicolumn{6}{|c|}{ Mean ( \pm standard deviation) change in eGFR (mL/min) } \\
\hline Post-op 7 days & $+2.70 \pm 20.6$ & $-7.21 \pm 17.2$ & 0.153 & $+0.7 \pm 13.2$ & 0.820 \\
\hline Post-op 30 days & $-5.00 \pm 14.6$ & $-8.46 \pm 13.2$ & 0.710 & $-9.18 \pm 8.90$ & 0.527 \\
\hline Post-op 60 days & $+1.13 \pm 10.2$ & $-9.90 \pm 12.2$ & 0.006 & $-6.87 \pm 10.3$ & 0.016 \\
\hline Post-op 90 days & $+3.47 \pm 12.5$ & $-1.70 \pm 13.9$ & 0.312 & $+5.15 \pm 10.3$ & 0.298 \\
\hline
\end{tabular}

Abbreviations: eGFR = estimated glomerular filtration rate; $\mathrm{HC}=$ hilar clamping; N/A = not applicable; SRPC = selective renal parenchymal clamping

* Comparison between SRPC and HC - cold ischaemia

+ Comparison between SRPC and HC - warm ischaemia

both cold $(\mathrm{P}=0.006)$ and warm ischaemia $(\mathrm{P}=0.016)$ when compared with SRPC. No acute kidney injury occurred during the early postoperative period after parenchymal clamping, while there were seven (9.7\%) cases of acute kidney injury in HC.

Overall $70 \%$ were renal cell carcinoma in SRPC. All tumours were pathological T1 disease with $92.9 \%$ in stage T1a. The mean pathological tumour size was $26.8 \mathrm{~mm}$. No patients in the SRPC group had a positive surgical margin or developed local recurrence or metastasis.

\section{Discussion}

This was a feasibility and safety study that showed the initial promising result of regional ischaemia achieved by SRPC using an adjustable kidney clamp. The concept of regional ischaemia is indeed not new and different instruments have been used successfully in other centres for partial nephrectomy.
It was first described by $\mathrm{Semb}^{8}$ in 1956 using manual compression. A self-made clamp with two remodelled malleable retractors ${ }^{4}$ and use of Rumel tourniquet have also been reported. ${ }^{9}$ More recently open $^{10}$ and laparoscopic Satinsky vascular clamps ${ }^{11}$ have been used. A Nussbaum clamp was used by Simon et al in $2008^{12}$ in open partial nephrectomy, normally intended for intestinal clamping during general surgery. They later modified this to the laparoscopic Simon clamp with a ratchet mechanism similar to ours. ${ }^{13}$ It consists of a pair of jaws $100-\mathrm{mm}$ long, one straight and the other one curved. Blood loss was minimal and no complications occurred in three cases. Recently the first study comparing parenchymal clamping with $\mathrm{HC}$ for robot-assisted laparoscopic partial nephrectomy was published. ${ }^{14}$ It showed that parenchymal clamping was associated with a shorter operating time and better preserved immediate postoperative renal function. Our method of SRPC using an adjustable kidney clamp 
has the merit of allowing flexible control with different degrees of tightness on the parenchyma during tumour excision, collecting system repair, and renorrhaphy. The degree of regional ischaemia can thus be minimised. Furthermore, the clamp serves as a mount for controlling the kidney's position during the procedure, mimicking the surgeon's hand directly holding the kidney and keeping it in a stable position during tumour excision and renorrhaphy, which is particularly useful in a laparoscopic setting.

\section{Tumour characteristics}

Utilisation of the kidney clamp is feasible for tumours with certain characteristics. As illustrated in Table 2, favourable tumour features include laterally located, polar region, and exophytic. Use in tumours that are located near the hilum, mid pole, or medial side is generally contra-indicated. ${ }^{13}$ Recently, different nephrometry scores have been increasingly used to describe tumour complexity in partial nephrectomies. ${ }^{6}$ The PADUA nephrometry score takes several variables into account, including the longitudinal location, the rim location, the relationship with the renal sinus and collecting system, percentage of tumour extending into the kidney, the anterior or posterior location, and the tumour diameter. A higher score is associated with greater risk of complications, ${ }^{6}$ externally validated by other study. ${ }^{15}$ The PADUA nephrometry score in the SRPC group was significantly lower in this study. It may have been that these tumours were technically less challenging, and reflects the limitations of the clamp as the hilum and ureter have to be spared during clamp application, therefore not all tumour locations are feasible. Nonetheless in selected cases, SRPC offers an easy and safe way of performing NSS. Currently no particular cut-off value of nephrometry score is used to determine the method of vascular control. Future studies are needed to deduce the selection criteria in which SRPC could be feasible and safely performed. This would be more objective and could facilitate the widespread adoption of the technique.

\section{Versatility in surgical approaches}

The kidney clamp is reusable and can be used regardless of the surgical approach. In the current study, seven patients had open surgery, nine had robot-assisted laparoscopic surgery, and four had pure laparoscopic surgery. In our experience, no adjustment to its application is required, regardless of surgical approach. This versatility allows the surgeon to be flexible when deciding the surgical approach.

\section{Avoid global renal ischaemia}

Another obvious benefit with the kidney clamp was the avoidance of whole kidney ischaemia. ${ }^{16}$ This was especially true for laparoscopic or robot-assisted cases in which only warm ischaemia was permitted. While cold ischaemia can be up to 3 hours, warm ischaemia is classically limited to 30 minutes.$^{17}$ This is undoubtedly one of the important stresses for the surgeons during partial nephrectomy. Recent studies have even shown that every minute of ischaemia can have a significant impact on postoperative renal function. Longer warm ischaemia is associated with acute kidney failure, with an odds ratio of 1.05 for each 1-minute increase. ${ }^{3}$ Regional ischaemia spares most of the non-tumour baring area from ischaemic injury. Animal study has reported the change in serum creatinine and intra-operative oxygenation profiles to be improved with parenchymal clamping or partial renal artery clamping, compared with complete renal artery clamping. ${ }^{18}$ In this study, early postoperative renal function was satisfactory after parenchymal clamping with minimal changes in eGFR. No patients experienced acute kidney injury during the early postoperative period. Postoperative renal function was mostly comparable between the groups (Table 4). There was significant deterioration in eGFR for HC $(\mathrm{P}=0.006$ and 0.016 for cold and warm ischaemia, respectively) at postoperative 60 days when compared with SRPC. This benefit in SRPC, however, failed to translate into a long-term renal function improvement as shown by 90-day renal function. The significance of this apparent transient benefit was not clear and might have been confounded by different factors in this retrospective study. By accumulating more cases and a longer follow-up, we believe the renal parenchymal clamp will be shown to better preserve renal function for partial nephrectomy in the long term.

\section{Safety}

There was no slippage or accidental loosening of the parenchymal clamp during tumour dissection and renorrhaphy. No cases required any additional hilar control. In terms of the oncological control, the parenchymal clamps did not lead to a higher positive margin rate, local recurrence rate, or metastases. On the contrary, we expect it to be lower, as the parenchymal clamp allows a more comfortable tumour dissection with less time constraints. This may improve the dissection result and lead to reduced positive surgical margin and better tumour control as the surgeon becomes more experienced.

\section{Surgical outcomes}

The mean operating time was reasonably short at 207 minutes. This was mainly attributed by the time saved for the tedious and sometimes risky hilar dissection. ${ }^{19}$ Renal cooling with ice was also unnecessary and further reduced the overall operating time. The lower estimated blood loss could be explained by the avoidance of $\mathrm{HC}$, as vascular 
injury during $\mathrm{HC}$ can lead to profuse bleeding ${ }^{10}$ or even renal artery dissection.

The study result of a shortened operating time and lower estimated blood loss needs to be interpreted with caution in view of several limitations of our study. First, it was a retrospective study and the sample size for SRPC was small. Moreover parenchymal clamping was done for less complex tumours. This difference in complexity might have contributed to the smaller blood loss and shorter operating time, as well as the preservation of renal function as less volume of renal parenchyma was removed. Another significant limitation was the lack of volumetric analysis, which rendered the renal function comparison between two groups difficult. A randomised, prospective study is required to truly compare the two methods after accumulating more clinical experience.

\section{Road to zero ischaemia}

Recently partial nephrectomy with zero ischaemia was reported, combining the use of selective arterial clamping and controlled hypotension. ${ }^{20}$ Outcomes were favourable with a mean absolute and percentage change in preoperative and 4-month postoperative eGFR of $-11.4 \mathrm{~mL} / \mathrm{min} / 1.73 \mathrm{~m}^{2}$ and $13 \%$, respectively. Nonetheless, this technique is technically demanding and requires a steep learning curve. Its utilisation is also limited to robot-assisted or laparoscopic surgery as a magnified view is essential for the meticulous vascular dissection. On the contrary, the kidney clamp in our study provides a relatively simpler way to perform partial nephrectomy without $\mathrm{HC}$, with a reasonable postoperative renal function outcome. This kidney clamp is undoubtedly an important addition to the surgical armamentarium in the evolvement of partial nephrectomy with ultimately zero ischaemia.

\section{Conclusions}

Partial nephrectomy using parenchymal clamping as a means of vascular control is safe and feasible in selected cases with peripherally located and exophytic tumours. It could be used in various surgical approaches to achieve regional ischaemia. The postoperative renal function and oncological control in this initial experience were satisfactory.

\section{Declaration}

All authors have disclosed no conflicts of interest.

\section{References}

1. Uzzo RG, Novick AC. Nephron sparing surgery for renal tumors: indications, techniques and outcomes. J Urol 2001;166:6-18.

2. Campbell SC, Novick AC, Belldegrun A, et al. Guideline for management of the clinical $\mathrm{T} 1$ renal mass. J Urol
2009;182:1271-9.

3. Thompson RH, Lane BR, Lohse CM, et al. Every minute counts when the renal hilum is clamped during partial nephrectomy. Eur Urol 2010;58:340-5.

4. Selikowitz SM. A simple partial nephrectomy clamp. J Urol 1995;154:489-90.

5. Levey AS, Bosch JP, Lewis JB, Greene T, Rogers N, Roth D. A more accurate method to estimate glomerular filtration rate from serum creatinine: a new prediction equation. Modification of Diet in Renal Disease Study Group. Ann Intern Med 1999;130:461-70.

6. Ficarra V, Novara G, Secco S, et al. Preoperative aspects and dimensions used for an anatomical (PADUA) classification of renal tumours in patients who are candidates for nephron-sparing surgery. Eur Urol 2009;56:786-93.

7. Clavien PA, Barkun J, de Oliveira ML, et al. The ClavienDindo classification of surgical complications: five-year experience. Ann Surg 2009;250:187-96.

8. Semb C. Partial resection of the kidney: anatomical, physiological and clinical aspects. Ann R Coll Surg Engl 1956;19:137-55.

9. Gill IS, Munch LC, Clayman RV, McRoberts JW, Nickless B, Roemer FD. A new renal tourniquet for open and laparoscopic partial nephrectomy. J Urol 1995;154:1113-6.

10. Denardi F, Borges GM, Silva W Jr, et al. Nephron-sparing surgery for renal tumours using selective renal parenchymal clamping. BJU Int 2005;96:1036-9.

11. Verhoest G, Manunta A, Bensalah K, et al. Laparoscopic partial nephrectomy with clamping of the renal parenchyma: initial experience. Eur Urol 2007;52:1340-6.

12. Simon J, dePetriconi R, Rinnab L, Hautmann RE, Kurtz F. Optimizing selective renal clamping in nephron-sparing surgery using the Nussbaum clamp. Urology 2008;71:11968.

13. Simon J, Bartsch G Jr, Finter F, Hautmann R, de Petriconi R. Laparoscopic partial nephrectomy with selective control of the renal parenchyma: initial experience with a novel laparoscopic clamp. BJU Int 2009;103:805-8.

14. Hsi RS, Macleod LC, Gore JL, Wright JL, Harper JD. Comparison of selective parenchymal clamping to hilar clamping during robotic-assisted laparoscopic partial nephrectomy. Urology 2014;83:339-44.

15. Tyritzis SI, Papadoukakis S, Katafigiotis I, et al. Implementation and external validation of Preoperative Aspects and Dimensions Used for an Anatomical (PADUA) score for predicting complications in 74 consecutive partial nephrectomies. BJU Int 2012;109:1813-8.

16. George AK, Herati AS, Srinivasan AK, et al. Perioperative outcomes of off-clamp vs complete hilar control laparoscopic partial nephrectomy. BJU Int 2013;111:E23541.

17. Novick AC. Renal hypothermia: in vivo and ex vivo. Urol Clin North Am 1983;10:637-44.

18. Raman JD, Bensalah K, Bagrodia A, et al. Comparison of tissue oxygenation profiles using 3 different methods of vascular control during porcine partial nephrectomy. Urology 2009;74:926-31.

19. Mejean A, Vogt B, Cazin S, Balian C, Poisson JF, Dufour B. Nephron sparing surgery for renal cell carcinoma using selective renal parenchymal clamping. J Urol 2002;167:2345 .

20. Gill IS, Patil MB, Abreu AL, et al. Zero ischemia anatomical partial nephrectomy: a novel approach. J Urol 2012;187:807-14. 